\title{
Preexisting and de novo humoral immunity to SARS-CoV-2 in humans
}

\author{
Kevin W. Ng1*, Nikhil Faulkner ${ }^{1 *}$, Georgina H. Cornish'*, Annachiara Rosa ${ }^{2 *}$, Ruth Harvey³, Saira Hussain ${ }^{3}$, \\ Rachel Ulferts ${ }^{9}$, Christopher Earl ${ }^{4}$, Antoni G. Wrobel ${ }^{5}$, Donald J. Benton ${ }^{5}$, Chloe Roustan ${ }^{6}$, William Bolland, \\ Rachael Thompson', Ana Agua-Doce ${ }^{7}$, Philip Hobson ${ }^{7}$, Judith Heaney ${ }^{13}$, Hannah Rickman ${ }^{13}$, Stavroula \\ Paraskevopoulou ${ }^{13}$, Catherine F. Houlihan ${ }^{13,14}$, Kirsty Thomson ${ }^{13}$, Emilie Sanchez ${ }^{13}$, Gee Yen Shin ${ }^{13}$, Moira J. \\ Spyer $^{13,15}$, Dhira Joshi ${ }^{8}$, Nicola O'Reilly ${ }^{8}$, Philip A. Walker ${ }^{6}$, Svend Kjaer ${ }^{6}$, Andrew Riddell' Catherine Moore $^{16}$, \\ Bethany R. Jebson $^{17,19}$, Meredyth Wilkinson ${ }^{17,19}$, Lucy R. Marshall ${ }^{17,19}$, Elizabeth C. Rosser ${ }^{17,18}$, Anna \\ Radziszewska $^{17,18}$, Hannah Peckham ${ }^{17,18}$, Coziana Ciurtin ${ }^{17,18}$, Lucy R. Wedderburn ${ }^{17,19}$, Rupert Beale ${ }^{9}$, Charles \\ Swanton $^{10}$, Sonia Gandhi1" ${ }^{11}$ Brigitta Stockinger ${ }^{12}$, John McCauley ${ }^{3}$, Steve J. Gamblin ${ }^{5}$, Laura E. McCoy ${ }^{14}+$, Peter \\ Cherepanov $^{2}$, Eleni Nastouli ${ }^{13,15}$, George Kassiotis ${ }^{1,20} \uparrow$
}

${ }^{1}$ Retroviral Immunology, The Francis Crick Institute, London NW1 1AT, UK. ${ }^{2}$ Chromatin Structure and Mobile DNA Laboratory, The Francis Crick Institute, London NW1 1AT, UK. ${ }^{3}$ Worldwide Influenza Centre, The Francis Crick Institute, London NW1 1AT, UK. ${ }^{5}$ Signalling and Structural Biology Laboratory, The Francis Crick Institute, London NW1 1AT, UK. Structural Biology of Disease Processes Laboratory, The Francis Crick Institute, London NW1 1AT, UK. 6Structural Biology STP, The Francis Crick Institute, London NW1 1AT, UK. ${ }^{7}$ Flow Cytometry STP, The Francis Crick Institute, London NW1 1AT, UK. ${ }^{8}$ Peptide Chemistry, The Francis Crick Institute, London NW1 1AT, UK. ${ }^{9}$ Cell Biology of Infection Laboratory, The Francis Crick Institute, London NW1 1AT, UK. ${ }^{10} \mathrm{Cancer}$ Evolution and Genome Instability Laboratory, The Francis Crick Institute, London NW1 1AT, UK. ${ }^{11}$ Neurodegeneration Biology Laboratory, The Francis Crick Institute, London NW1 1AT, UK. ${ }^{12}$ AhRimmunity Laboratory, The Francis Crick Institute, London NW1 1AT, UK. ${ }^{13}$ University College London Hospitals (UCLH) NHS Trust, London NW1 2BU, UK. ${ }^{14}$ Division of Infection and Immunity, University College London (UCL), London WC1E 6BT, UK. ${ }^{15}$ Department of Population, Policy and Practice, Great Ormond Street Institute for Child Health (ICH), UCL, London WC1N 1EH, UK. ${ }^{16 P u b l i c ~ H e a l t h ~ W a l e s, ~ U n i v e r s i t y ~}$ Hospital of Wales, Cardiff CF14 4XW, UK. ${ }^{17}$ Centre for Adolescent Rheumatology Versus Arthritis at UCL, UCLH, Great Ormond Street Hospital (GOSH), London WC1N 3JH, UK. ${ }^{18}$ Centre for Rheumatology Research, Division of Medicine, UCL, London, WC1E 6BT, UK. ${ }^{19}$ UCL Great Ormond Street Institute for Child Health (ICH), UCL, London WC1N 1EH, UK. ${ }^{20}$ Department of Medicine, Faculty of Medicine, Imperial College London, London W2 1PG, UK.

*These authors contributed equally to this work.

†Corresponding author. Email: george.kassiotis@crick.ac.uk (G.K.); e.nastouli@ucl.ac.uk (E.N.); peter.cherepanov@crick.ac.uk (P.C.); I.mccoy@ucl.ac.uk (L.E.M.)

Zoonotic introduction of novel coronaviruses may encounter preexisting immunity in humans. Using diverse assays for antibodies recognizing SARS-CoV-2 proteins, we detect preexisting humoral immunity. SARSCoV-2 spike glycoprotein (S)-reactive antibodies were detectable by a flow cytometry-based method in SARS-CoV-2-uninfected individuals and were particularly prevalent in children and adolescents. They were predominantly of the IgG class and targeted the S2 subunit. By contrast, SARS-CoV-2 infection induced higher titers of SARS-CoV-2 S-reactive IgG antibodies, targeting both the S1 and S2 subunits, and concomitant IgM and IgA antibodies, lasting throughout the observation period. Notably, SARS-CoV-2uninfected donor sera exhibited specific neutralizing activity against SARS-CoV-2 and SARS-CoV-2 S pseudotypes. Distinguishing preexisting and de novo immunity will be critical for our understanding of susceptibility to and the natural course of SARS-CoV-2 infection.

Immune cross-reactivity among seasonally spreading human coronaviruses (HCoVs) has long been hypothesized to provide effective, but transient cross-protection against distinct HCoVs $(1,2)$. To determine the degree of cross-reactivity between HCoVs and SARS-CoV-2, we developed a flow cytometry-based assay for SARS-CoV-2-binding antibodies. The main target for such antibodies is the spike glycoprotein (S), which is proteolytically processed into the $\mathrm{S} 1$ and $\mathrm{S} 2$ subunits, mediating target cell attachment and entry, respectively.

The S1-specific CR3022 antibody stained a smaller percentage of SARS-CoV-2 S-expressing HEK293T cells and with lower intensity than COVID-19 convalescent sera (fig. S1), indicating that polyclonal IgG antibodies targeted a wider range of epitopes naturally processed and displayed on these cells. This assay also detected SARS-CoV-2 S-reactive IgM and IgA antibodies in COVID-19 convalescent sera (fig. S2). Indeed, the presence of SARS-CoV-2 S-reactive antibodies of all three Ig classes $\left(\operatorname{IgG}^{+} \operatorname{IgM}{ }^{+} \operatorname{IgA}^{+}\right)$distinguished COVID-19 sera from control sera with a high degree of sensitivity and specificity (Fig. 1A and fig. S3). All 156 seroconverted COVID-19 patients had contemporaneous IgG, IgM, and IgA responses to SARS-CoV-2 S throughout the observation period, with the exception of two patients, who only had IgG antibodies (figs. S4 and S5). One of these patients was a bone-marrow-transplant recipient who experienced $\mathrm{HCoV}$ infection a month prior to SARS-CoV-2 infection (fig. S6). Remarkably, a small proportion of SARS-CoV-2-uninfected patients, sampled before or during the early spread of SARS-CoV-2 in the UK 
(table S1), also had SARS-CoV-2 S-binding IgG, but not IgM or IgA antibodies (Fig. 1A), suggesting the presence of crossreactive immunological memory.

The S2 subunit exhibits a higher degree of homology among coronaviruses than $\mathrm{S} 1$ (fig. S7) and was likely the main target of cross-reactive antibodies. Competition with recombinant soluble $\mathrm{S} 1$ or $\mathrm{S} 2$, at doses that blocked binding of specific monoclonal antibodies (fig. S8), did not affect the frequency of cells stained with COVID-19 patient sera, although the intensity of staining was reduced by $31 \%$ and $37 \%$, respectively (Fig. 1, B to D), indicating recognition of both $\mathrm{S} 1$ and S2. By contrast, soluble S2 completely abolished staining with SARS-CoV-2-uninfected patient sera, whereas soluble S1 had no effect (Fig. 1, B to D). Thus, SARS-CoV-2-uninfected patient sera cross-reacts with SARS-CoV-2 S2 and COVID-19 patient sera additionally recognizes $\mathrm{S} 1$.

SARS-CoV-2 S-reactive IgG antibodies were detected by flow cytometry in 5 of 34 SARS-CoV-2-uninfected individuals with RT-qPCR-confirmed HCoV infection, as well as in 1 of 31 individuals without recent $\mathrm{HCoV}$ infection (Fig. 2A and fig. S4A). This suggested that cross-reactivity may have persisted from earlier $\mathrm{HCoV}$ infections, rather than having been induced by the most recent one.

To confirm antibody cross-reactivity using an independent assay, we developed ELISAs using recombinant SARSCoV-2 stabilized trimeric S ectodomain, S1, receptor-binding domain (RBD), or nucleoprotein (N). Rates of IgG seropositivity by SARS-CoV-2 S1-coated ELISA were congruent with, but generally lower than those by flow cytometry (fig. S9). The three SARS-CoV-2-uninfected individuals with the highest cross-recognition of $\mathrm{S}$ by flow cytometry, plus an additional four individuals, had ELISA-detectable IgG antibodies against SARS-CoV-2 S ectodomain, as well as N (Fig. 2A and fig. S4, B to D). By contrast, none of the control samples had ELISA-detectable IgG antibodies against the less conserved SARS-CoV-2 S1 or RBD (Fig. 2A and fig. S4, B to D).

The prevalence of such cross-reactive antibodies was further examined in additional healthy donor cohorts (table S1). Among 50 SARS-CoV-2-uninfected pregnant women, sampled in May 2018, five showed evidence for SARS-CoV-2 Sreactive IgG, but not IgM or IgA antibodies (Fig. 2B and fig. S10). In a separate cohort of 101 SARS-CoV-2-uninfected donors, sampled in May 2019, three had SARS-CoV-2 S-reactive IgG antibodies (fig. S11), which did not correlate with antibodies to diverse viruses and bacteria also present in several of these samples. SARS-CoV-2 S-reactive IgM and IgA were also detected in two of these donors, albeit at considerably lower levels than in COVID-19 patients (fig. S11), suggestive of recent or ongoing response. In an additional cohort of 13 donors recently infected with HCoVs, only one had SARSCoV-2 S-reactive IgG antibodies, and these at very low levels (fig. S12). This suggested that their emergence was not simply a common transient event following each $\mathrm{HCoV}$ infection in this age group (median age 51 years; table S1). Instead, given that $\mathrm{HCoV}$-reactive antibodies are present in virtually all adults (3-5), the rarity of SARS-CoV-2 S cross-reactivity (16 of $302 ; 5.29 \%$ ), indicates additional requirements, such as random B cell receptor repertoire focusing or frequency of $\mathrm{HCoV}$ infection, rather than time since the last $\mathrm{HCoV}$ infection. Indeed, the frequency of $\mathrm{HCoV}$ infection displays a characteristic age distribution, being the highest in children and adolescents $(1,4-8)$. We therefore examined a cohort of younger SARS-CoV-2-uninfected healthy donors (aged 1-16 years; table S1), sampled between 2011 and 2018. Remarkably, at least 21 of these 48 donors had detectable levels of SARSCoV-2 S-reactive IgG antibodies (Fig. 2, C to E), whereas only one of an additional cohort of 43 young adults (aged 17-25 years; table S1) had such antibodies (Fig. 2F). Staining with sera from SARS-CoV-2-uninfected children and adolescents was specific to HEK293T cells expressing SARS-CoV-2 S, but not the unrelated HERV-K113 envelope glycoprotein, and was outcompeted by soluble SARS-CoV-2 S2 (fig. S13). The prevalence of SARS-CoV-2 S-reactive IgG antibodies peaked at $62 \%$ between 6 and 16 years of age (Fig. 2F), when HCoV seroconversion in this age group also peaks $(3,4,6,7)$, and was significantly higher than in adults $(P<0.00001$, Fisher's exact test).

To probe the potential consequences of antibody cross-reactivity, we examined the ability of preexisting antibodies to inhibit SARS-CoV-2 entry into HEK293T cells (fig. S14 and supplementary text). Although not expected to directly inhibit RBD-mediated cell attachment, S2-targeting antibodies that can neutralize SARS-CoV-2 have recently been discovered $(9,10)$. HEK293T cell infection with SARS-CoV-2 S pseudotypes was efficiently inhibited by sera from seroconverted $\left(\mathrm{Ab}^{+}\right)$COVID-19 patients, but not from those that had not yet seroconverted $\left(\mathrm{Ab}^{-}\right)$(Fig. $\left.3 \mathrm{~A}\right)$. Surprisingly, sera from SARS-CoV-2-uninfected donors with SARS-CoV-2 S-reactive antibodies also neutralized these pseudotypes, whereas none of the sera neutralized vesicular stomatitis virus (VSV) glycoprotein pseudotypes (Fig. 3A). Comparable neutralization of SARS-CoV-2 S pseudotypes was also observed with sera from SARS-CoV-2-uninfected adolescents (Fig. 3A). Moreover, the majority of sera from SARS-CoV-2-uninfected donors with flow cytometry-detectable cross-reactive antibodies also neutralized authentic SARS-CoV-2 infection of Vero E6 cells, albeit on average less potently than COVID-19 patient sera (Fig. 3B). By contrast, sera from SARS-CoV-2-uninfected patients without cross-reactive antibodies exhibited no neutralizing activity (Fig. 3B). Antiviral antibodies may also enhance viral entry by $\mathrm{Fc}$ receptor-mediated antibody-dependent enhancement (ADE). However, entry of SARS-CoV-2 S pseudotypes was not enhanced by either COVID-19 patient or SARS-CoV-2-uninfected patient sera in Fc $\gamma$ RIIA-expressing K-562 cells (fig. S15). 
Collectively, these findings highlighted functionally relevant antigenic epitopes conserved within the S2. Over its entire length, SARS-CoV-2 S exhibits marginally closer homology with the $\mathrm{S}$ proteins of betacoronaviruses $\mathrm{HCoV}$ OC43 and HCoV-HKU1, than of alphacoronaviruses HCoVNL63 and HCoV-229E (fig. S16A). To probe shared epitopes, we constructed overlapping peptide arrays spanning the last 743 amino acids of SARS-CoV-2 S (fig. S16B). Multiple putative epitopes were differentially recognized by sera with cross-reactive antibodies $\left(\mathrm{Ab}^{+}\right)$, were reasonably conserved, and most mapped to the surface of S2 (Fig. 4, A and B, and table S2). Of note, an epitope overlapping the S2 fusion peptide was also recently identified as cross-reactive with the corresponding peptides from $\mathrm{HCoV}-\mathrm{OC} 43$ and $\mathrm{HCoV}-229 \mathrm{E}$ (11). Cross-reactivity with the identified epitopes was further supported by ELISAs coated with synthetic peptides (fig. S17).

As expected (3-5), reactivity with one or more HCoVs was detectable by flow cytometry in all sera (Fig. 4D and fig. S18). However, IgG and IgA reactivity against $\mathrm{HCoVs}$ was higher in SARS-CoV-2-uninfected adults with, than without SARS-CoV-2reactive IgG $\left(P=1.4 \times 10^{-6}\right.$ for IgG and $P=0.017$ for IgA, Student's $t$ test), and in SARS-CoV-2-uninfected children or adolescents with, than without SARS-CoV-2-reactive IgG $(P=0.010$ for IgG and $P=0.021$ for IgA, Student's $t$ test) (Fig. 4D), supporting a direct link between the two. Accordingly, IgG reactivity against each $\mathrm{HCoV}$ type was independently correlated with the presence of SARS-CoV-2-reactive antibodies (Fig. 4D).

Our results from multiple independent assays demonstrated the presence of preexisting antibodies recognizing SARS-CoV-2 in uninfected individuals. Identification of conserved epitopes in S2 targeted by neutralizing antibodies may hold promise for a universal vaccine protecting against current, as well as future CoVs. Together with preexisting T cell (12-14) and B cell memory $(10,15)$, antibody cross-reactivity between seasonal HCoVs and SARS-CoV-2 may have important ramifications for natural infection. Epidemiological studies of $\mathrm{HCoV}$ transmission suggest that cross-protective immunity is unlikely to be sterilizing or longlasting (8), which is also supported by repeated reinfection $(2$, 16). Nevertheless, prior immunity induced by one $\mathrm{HCoV}$ can reduce the transmission of homologous and heterologous HCoVs, and ameliorate the symptoms where transmission is not prevented $(1,2)$. A possible modification of COVID-19 severity by prior $\mathrm{HCoV}$ infection may account for the age distribution of COVID-19 susceptibility, where higher $\mathrm{HCoV}$ infection rates in children than in adults $(4,6)$ correlates with relative protection from COVID-19 (17) and may also shape seasonal and geographical patterns of transmission. It is, therefore, imperative that any effect, positive or negative, of preexisting $\mathrm{HCoV}$-elicited immunity on the natural course of SARS-CoV-2 infection be fully delineated.

\section{REFERENCES AND NOTES}

1. R. W. Aldridge, D. Lewer, S. Beale, A. M. Johnson, M. Zambon, A. C. Hayward, E. B. Fragaszy, Seasonality and immunity to laboratory-confirmed seasonal coronaviruses (HCoV-NL63, HCoV-OC43, and HCoV-229E): Results from the Flu
Watch cohort study. Wellcome Open Res. 5, 52 (2020). doi:10.12688/wellcomeopenres. 15812.1

2. K. A. Callow, H. F. Parry, M. Sergeant, D. A. Tyrrell, The time course of the immune response to experimental coronavirus infection of man. Epidemiol. Infect. 105, 435-446 (1990). doi:10.1017/S0950268800048019 Medline

3. E. G. Severance, I. Bossis, F. B. Dickerson, C. R. Stallings, A. E. Origoni, A. Sullens, R. H. Yolken, R. P. Viscidi, Development of a nucleocapsid-based human coronavirus immunoassay and estimates of individuals exposed to coronavirus in a U.S. metropolitan population. Clin. Vaccine Immunol. 15, 1805-1810 (2008). doi:10.1128/CVI.00124-08 Medline

4. R. Dijkman, M. F. Jebbink, N. B. El Idrissi, K. Pyrc, M. A. Müller, T. W. Kuijpers, H. L. Zaaiier, L. van der Hoek, Human coronavirus NL63 and 229E seroconversion in children. J. Clin. Microbiol. 46, 2368-2373 (2008). doi:10.1128/JCM.00533-08 Medline

5. A. T. Huang, B. Garcia-Carreras, M. D. T. Hitchings, B. Yang, L. C. Katzelnick, S. M. Rattigan, B. A. Borgert, C. A. Moreno, B. D. Solomon, L. Trimmer-Smith, V Etienne, I. Rodriguez-Barraquer, J. Lessler, H. Salje, D. S. Burke, A. Wesolowski, D. A. T. Cummings, A systematic review of antibody mediated immunity to coronaviruses: Kinetics, correlates of protection, and association with severity. Nat. Commun. 11, 4704 (2020). doi:10.1038/s41467-020-18450-4 Medline

6. N. Friedman, H. Alter, M. Hindiyeh, E. Mendelson, Y. Shemer Avni, M. Mandelboim, Human coronavirus infections in Israel: Epidemiology, clinical symptoms and summer seasonality of HCoV-HKU1. Viruses 10, 515 (2018). do:i:10.3390/v10100515 Medline

7. S. Nickbakhsh et al., Epidemiology of seasonal coronaviruses: Establishing the context for COVID-19 emergence. J. Infect. Dis. (2020).

8. A. S. Monto, P. M. De Jonge, A. P. Callear, L. A. Bazzi, S. B. Capriola, R. E. Malosh, E. T. Martin, J. G. Petrie, Coronavirus occurrence and transmission over 8 years in the HIVE cohort of households in Michigan. J. Infect. Dis. 222, 9-16 (2020). doi:10.1093/infdis/jiaa161 Medline

9. X. Chi, R. Yan, J. Zhang, G. Zhang, Y. Zhang, M. Hao, Z. Zhang, P. Fan, Y. Dong, Y Yang, Z. Chen, Y. Guo, J. Zhang, Y. Li, X. Song, Y. Chen, L. Xia, L. Fu, L. Hou, J. Xu, C. Yu, J. Li, Q. Zhou, W. Chen, A neutralizing human antibody binds to the Nterminal domain of the Spike protein of SARS-CoV-2. Science 369, 650-655 (2020). doi:10.1126/science abc6952 Medline

10. G. Song, W. He, S. Callaghan, F. Anzanello, D. Huang, J. Ricketts, J. L. Torres, N. Beutler, L. Peng, S. Vargas, J. Cassell, M. Parren, L. Yang, C. Ignacio, D. M. Smith, J. E. Voss, D. Nemazee, A. B. Ward, T. Rogers, D. R. Burton, R. Andrabi, Crossreactive serum and memory $B$ cell responses to spike protein in SARS-CoV-2 and endemic coronavirus infection. bioRxiv 308965 [Preprint]. 23 September 2020; https://doi.org/10.1101/2020.09222308965.

11. E. Shrock, E. Fujimura, T. Kula, R. T. Timms, I.-H. Lee, Y. Leng, M. L. Robinson, B. M. Sie, M. Z. Li, Y. Chen, J. Logue, A. Zuiani, D. McCulloch, F. J. N. Lelis, S. Henson, D. R. Monaco, M. Travers, S. Habibi, W. A. Clarke, P. Caturegli, O. Laeyendecker, A. Piechocka-Trocha, J. Li, A. Khatri, H. Y. Chu, A.-C. Villani, K. Kays, M. B. Goldberg, N. Hacohen, M. R. Filbin, X. G. Yu, B. D. Walker, D. R. Wesemann, H. B. Larman, J. A. Lederer, S. J. Elledge; MGH COVID-19 Collection \& Processing Team, Viral epitope profiling of COVID-19 patients reveals cross-reactivity and correlates of severity. Science eabd4250 (2020). doi:10.1126/science.abd4250 Medline

12. A. Grifoni, D. Weiskopf, S. I. Ramirez, J. Mateus, J. M. Dan, C. R. Moderbacher, S. A. Rawlings, A. Sutherland, L. Premkumar, R. S. Jadi, D. Marrama, A. M. de Silva, A. Frazier, A. F. Carlin, J. A. Greenbaum, B. Peters, F. Krammer, D. M. Smith, S. Crotty, A. Sette, Targets of T cell responses to SARS-CoV-2 coronavirus in humans with COVID-19 disease and unexposed individuals. Cell 181, 14891501.e15 (2020). doi:10.1016/i.cell.2020.05.015 Medline

13. J. Braun, L. Loyal, M. Frentsch, D. Wendisch, P. Georg, F. Kurth, S. Hippenstiel, M. Dingeldey, B. Kruse, F. Fauchere, E. Baysal, M. Mangold, L. Henze, R. Lauster, M. A. Mall, K. Beyer, J. Röhmel, S. Voigt, J. Schmitz, S. Miltenyi, I. Demuth, M. A. Müller, A. Hocke, M. Witzenrath, N. Suttorp, F. Kern, U. Reimer, H. Wenschuh, C. Drosten, V. M. Corman, C. Giesecke-Thiel, L. E. Sander, A. Thiel, SARS-CoV-2reactive $T$ cells in healthy donors and patients with COVID-19. Nature (2020). doi:10.1038/s41586-020-2598-9 Medline

14. N. Le Bert, A. T. Tan, K. Kunasegaran, C. Y. L. Tham, M. Hafezi, A. Chia, M. H. Y. Chng, M. Lin, N. Tan, M. Linster, W. N. Chia, M. I.-C. Chen, L.-F. Wang, E. E. Ooi, S. Kalimuddin, P. A. Tambyah, J. G.-H. Low, Y.-J. Tan, A. Bertoletti, SARS-CoV-2- 
specific T cell immunity in cases of COVID-19 and SARS, and uninfected controls. Nature 584, 457-462 (2020). doi:10.1038/s41586-020-2550-z Medline

15. P. Nguyen-Contant, A. K. Embong, P. Kanagaiah, F. A. Chaves, H. Yang, A. R. Branche, D. J. Topham, M. Y. Sangster, S protein-reactive IgG and memory B cell production after human SARS-CoV-2 infection includes broad reactivity to the S2 subunit. mBio 11, e01991-e01920 (2020). doi:10.1128/mBio.01991-20 Medline

16. P. K. Kiyuka, C. N. Agoti, P. K. Munywoki, R. Njeru, A. Bett, J. R. Otieno, G. P. Otieno, E. Kamau, T. G. Clark, L. van der Hoek, P. Kellam, D. J. Nokes, M. Cotten, Human coronavirus NL63 molecular epidemiology and evolutionary patterns in rural coastal Kenya. J. Infect. Dis. 217, 1728-1739 (2018). doi:10.1093/infdis/iiy098 Medline

17. R. Castagnoli, M. Votto, A. Licari, I. Brambilla, R. Bruno, S. Perlini, F. Rovida, F. Baldanti, G. L. Marseglia, Severe acute respiratory syndrome coronavirus 2 (SARS-CoV-2) infection in children and adolescents: A systematic review. JAMA Pediatr. 174, 882-889 (2020). doi:10.1001/jamapediatrics.2020.1467 Medline

18. P. R. Grant, M. A. Turner, G. Y. Shin, E. Nastouli, L. J. Levett, Extraction-free COVID19 (SARS-CoV-2) diagnosis by RT-PCR to increase capacity for national testing programmes during a pandemic. bioRxiv 028316 [Preprint]. 9 April 2020; https://doi.org/10.1101/2020.04.06.028316.

19. K. Hanke, P. Kramer, S. Seeher, N. Beimforde, R. Kurth, N. Bannert, Reconstitution of the ancestral glycoprotein of human endogenous retrovirus $k$ and modulation of its functional activity by truncation of the cytoplasmic domain. J. Virol. 83 12790-12800 (2009). doi:10.1128/JVL.01368-09 Medline

20. J. ter Meulen, E. N. van den Brink, L. L. M. Poon, W. E. Marissen, C. S. W. Leung, F. Cox, C. Y. Cheung, A. Q. Bakker, J. A. Bogaards, E. van Deventer, W. Preiser, H. W. Doerr, V. T. Chow, J. de Kruif, J. S. M. Peiris, J. Goudsmit, Human monoclonal antibody combinationagainst SARS coronavirus: Synergy and coverage of escape mutants. PLOS Med. 3, e237 (2006). doi:10.1371/journal.pmed.0030237Medline

21. M. G. Joyce, R. S. Sankhala, W.-H. Chen, M. Choe, H. Bai, A. Hajduczki, L. Yan, S. L. Sterling, C. E. Peterson, E. C. Green, C. Smith, N. de Val, M. Amare, P. Scott, E. D. Laing, C. C. Broder, M. Rolland, N. L. Michael, K. Modjarrad, A cryptic site of vulnerability on the receptor binding domain of the SARS-CoV-2 spike glycoprotein. bioRxiv 992883 [Preprint]. 17 March 2020; https://doi.org/10.1101/2020.03.15.992883.

22. V. E. Pye, A. Rosa, C. Bertelli, W. B. Struwe, S. L. Maslen, R. Corey, I. Liko, M Hassall, G. Mattiuzzo, A. Ballandras-Colas, A. Nans, Y. Takeuchi, P. J. Stansfeld, J. M. Skehel, C. V. Robinson, M. Pizzato, P. Cherepanov, A bipartite structural organization defines the SERINC family of HIV-1 restriction factors. Nat. Struct. Mol. Biol. 27, 78-83 (2020). do::10.1038/s41594-019-0357-0 Medline

23. J. Pallesen, N. Wang, K. S. Corbett, D. Wrapp, R. N. Kirchdoerfer, H. L. Turner, C. A. Cottrell, M. M. Becker, L. Wang, W. Shi, W.-P. Kong, E. L. Andres, A. N. Kettenbach, M. R. Denison, J. D. Chappell, B. S. Graham, A. B. Ward, J. S. McLellan, Immunogenicity and structures of a rationally designed prefusion MERS-CoV spike antigen. Proc. Natl. Acad. Sci. U.S.A. 114, E7348-E7357 (2017). doi:10.1073/pnas.1707304114 Medline

24. D. Wrapp, N. Wang, K. S. Corbett, J. A. Goldsmith, C.-L. Hsieh, O. Abiona, B. S Graham, J. S. McLellan, Cryo-EM structure of the 2019-nCoV spike in the prefusion conformation. Science 367, 1260-1263 (2020). doi:10.1126/science. abb2507 Medline

25. Y. Lin, Y. Gu, S. A. Wharton, L. Whittaker, V. Gregory, X. Li, S. Metin, N. Cattle, R. S. Daniels, A. J. Hay, J. W. McCauley, Optimisation of a micro-neutralisation assay and its application in antigenic characterisation of influenza viruses. Influenza Other Respir. Viruses 9, 331-340 (2015). doi:10.1111/irv.12333 Medline

26. L. H. Evans, R. P. Morrison, F. G. Malik, J. Portis, W. J. Britt, A neutralizable epitope common to the envelope glycoproteins of ecotropic, polytropic, xenotropic, and amphotropic murine leukemia viruses. J. Virol. 64, 6176-6183 (1990). doi:10.1128/JVl.64.12.6176-6183.1990 Medline

27. M. Hoffmann, H. Kleine-Weber, S. Schroeder, N. Krüger, T. Herrler, S. Erichsen, T. S. Schiergens, G. Herrler, N.-H. Wu, A. Nitsche, M. A. Müller, C. Drosten, S. Pöhlmann, SARS-CoV-2 cell entry depends on ACE2 and TMPRSS2 and is blocked by a clinically proven protease inhibitor. Cell 181, 271-280.e8 (2020). doi:10.1016/i.cell.2020.02.052 Medline

28. X. Ou, Y. Liu, X. Lei, P. Li, D. Mi, L. Ren, L. Guo, R. Guo, T. Chen, J. Hu, Z. Xiang, Z. Mu, X. Chen, J. Chen, K. Hu, Q. Jin, J. Wang, Z. Qian, Characterization of spike glycoprotein of SARS-CoV-2 on virus entry and its immune cross-reactivity with
SARS-CoV. Nat. Commun. 11, 1620 (2020). doi:10.1038/s41467-020-15562-9 Medline

29. A. C. Walls, Y. J. Park, M. A. Tortorici, A. Wall, A. T. McGuire, D. Veesler. Structure, Function, and Antigenicity of the SARS-CoV-2 Spike Glycoprotein. Cell 181, 281292.e6 (2020). doi:10.1016/i.cell.2020.02.058 Medline

30. P. Zhou, X. L. Yang, X. G. Wang, B. Hu, L. Zhang, W. Zhang, H. R. Si, Y. Zhu, B. Li, C. L. Huang, H. D. Chen, J. Chen, Y. Luo, H. Guo, R. D. Jiang, M. Q. Liu, Y. Chen, X. R. Shen, X. Wang, X. S. Zheng, K. Zhao, Q. J. Chen, F. Deng, L. L. Liu, B. Yan, F. X. Zhan, Y. Y. Wang, G. F. Xiao, Z. L. Shi, A pneumonia outbreak associated with a new coronavirus of probable bat origin. Nature 579, 270-273 (2020). doi:10.1038/s41586-020-2012-7 Medline

31. K. Wang, W. Chen, Y.-S. Zhou, J.-Q. Lian, Z. Zhang, P. Du, L. Gong, Y. Zhang, H.-Y. Cui, J.-J. Geng, B. Wang, X.-X. Sun, C.-F. Wang, X. Yang, P. Lin, Y.-Q. Deng, D. Wei, X.-M. Yang, Y.-M. Zhu, K. Zhang, Z.-H. Zheng, J.-L. Miao, T. Guo, Y. Shi, J. Zhang, L. Fu, Q.-Y. Wang, H. Bian, P. Zhu, Z.-N. Chen, SARS-CoV-2 invades host cells via a novel route: CD147-spike protein. bioRxiv 988345 [Preprint]; 14 March 2020; https://doi.org/10.1101/2020.03.14.988345.

32. L. Cantuti-Castelvetri, R. Ojha, L. D. Pedro, M. Djannatian, J. Franz, S. Kuivanen, K. Kallio, T. Kaya, M. Anastasina, T. Smura, L. Levanov, L. Szirovicza, A. Tobi, H. Kallio-Kokko, P. Österlund, M. Joensuu, F. A. Meunier, S. Butcher, M. S. Winkler, B. Mollenhauer, A. Helenius, O. Gokce, T. Teesalu, J. Hepojoki, O. Vapalahti, C. Stadelmann, G. Balistreri, M. Simons, Neuropilin-1 facilitates SARS-CoV-2 cell entry and provides a possible pathway into the central nervous system. bioRxiv 137802 [Preprint]. 15 July 2020; https://doi.org/10.1101/2020.06.07.137802.

33. J. L. Daly, B. Simonetti, C. Antón-Plágaro, M. Kavanagh Williamson, D. K. Shoemark, L. Simón-Gracia, K. Klein, M. Bauer, R. Hollandi, U. F. Greber, P. Horvath, R. B. Sessions, A. Helenius, J. A. Hiscox, T. Teesalu, D. A. Matthews, A. D. Davidson, P. J. Cullen, Y. Yamauch, Neuropilin-1 is a host factor for SARS-CoV-2 infection. bioRxiv 134114 [Preprint]. 5 June 2020; https://doi.org/10.1101/2020.06.05.134114

34. M. C. Freeman, C. T. Peek, M. M. Becker, E. C. Smith, M. R. Denison, Coronaviruses induce entry-independent, continuous macropinocytosis. mBio 5, e01340-e14 (2014). doi:10.1128/mBio.01340-14 Medline

35. T. C. Nash, T. M. Gallagher, M. J. Buchmeier, MHVR-independent cell-cell spread of mouse hepatitis virus infection requires neutral pH fusion. Adv. Exp. Med. Biol. 380, 351-357 (1995). doi:10.1007/978-1-4615-1899-0 57 Medline

36. A. Grifoni, J. Sidney, Y. Zhang, R. H. Scheuermann, B. Peters, A. Sette, A Sequence Homology and Bioinformatic Approach Can Predict Candidate Targets for Immune Responses to SARS-CoV-2. Cell Host Microbe 27, 671-680.e2 (2020). doi:10.1016/i.chom.2020.03.002 Medline

37. A. G. Wrobel, D. J. Benton, P. Xu, C. Roustan, S. R. Martin, P. B. Rosenthal, J. J. Skehel, S. J. Gamblin, SARS-CoV-2 and bat RaTG13 spike glycoprotein structures inform on virus evolution and furin-cleavage effects. Nat. Struct. Mol. Biol. 27, 763-767 (2020). doi:10.1038/s41594-020-0468-7 Medline

38. Y. Cai, J. Zhang, T. Xiao, H. Peng, S. M. Sterling, R. M. Walsh Jr., S. Rawson, S. RitsVolloch, B. Chen, Distinct conformational states of SARS-CoV-2 spike protein. Science 369, 1586-1592 (2020). doi:10.1126/science.abd4251 Medline

39. B. Turoňová, M. Sikora, C. Schürmann, W. J. H. Hagen, S. Welsch, F. E. C. Blanc, S. von Bülow, M. Gecht, K. Bagola, C. Hörner, G. van Zandbergen, J. Landry, N. T. D. de Azevedo, S. Mosalaganti, A. Schwarz, R. Covino, M. D. Mühlebach, G. Hummer, J. Krijnse Locker, M. Beck, In situ structural analysis of SARS-CoV-2 spike reveals flexibility mediated by three hinges. Science 370, 203-208 (2020). doi:10.1126/science. abd5223 Medline

40. S. Klein, M. Cortese, S. L. Winter, M. Wachsmuth-Melm, C. J. Neufeldt, B. Cerikan, M. L. Stanifer, S. Boulant, R. Bartenschlager, P. Chlanda, SARS-CoV-2 structure and replication characterized by in situ cryoelectron tomography. bioRxiv 167064 [Preprint]. 16 August 2020; https://doi.org/10.1101/2020.06.23.167064.

\section{ACKNOWLEDGMENTS}

We thank L. James and J. Luptak for the SARV CoV2 N expression construct and M. Pizzato for the SARS CoV2 S cDNA. We also thank the entire CRICK COVID-19 Consortium. We are grateful for assistance from the Cell Services and High Throughput Screening facilities at the Francis Crick Institute and UCLH Biochemistry (A. Goyale and C. Wilson) and to Mr Michael Bennet and Mr Simon Caidan for training and support in the high-containment laboratory. Funding: 
This work was supported by a Centre of Excellence Centre for Adolescent Rheumatology Versus Arthritis grant, 21593, as well as support from the Great Ormond Street Childrens Charity, Cure JM Foundation and the NIHR Biomedical Research Centres at GOSH and UCLH. This work was supported by the Francis Crick Institute, which receives its core funding from Cancer Research UK, the UK Medical Research Council, and the Wellcome Trust. Author contributions: Experimental design, C.C., L.R.W., R.B., C.S., S.G., B.S., J.McC., S.J.G., L.E.McC., P.C., E.N., and G.K. Investigation, K.W.N., N.F., G.H.C., A.Ro., R.H., S.H., R.U., C.E., A.G.W., D.J.B., C.R., W.B., R.T., A.A.-D., P.H., and D.J. Reagents and Samples, J.H., H.R., S.P., C.F.H., K.T., E.S., G.Y.S., M.J.S., P.A.W., C.M., B.R.J., M.G.LI.W., L.R.M., E.C.R., A.Ra., and H.P. Writing, L.E.McC., P.C., E.N., and G.K., with contributions from C.C., L.R.W., K.W.N., N.F., and G.H.C. Supervision, N.O'R., S.K., A.Ri., C.C., L.R.W., R.B., C.S., S.G., B.S., J.McC., S.J.G., L.E.McC., P.C., E.N., and G.K. Competing interests: The authors declare no competing interests. Data and materials availability: All data are available in the main text or the supplementary materials. This work is licensed under a Creative Commons Attribution 4.0 International (CC BY 4.0) license, which permits unrestricted use, distribution, and reproduction in any medium, provided the original work is properly cited. To view a copy of this license, visit https://creativecommons. org/licenses/by/4.0/. This license does not apply to figures/photos/artwork or other content included in the article that is credited to a third party; obtain authorization from the rights holder before using such material.

\section{SUPPLEMENTARY MATERIALS}

science. sciencemag.org/cgi/content/full/science.abe1107/DC1

Materials and Methods

Supplementary Text

Figs. S1 to S18

Tables S1 and S2

References (18-40)

MDAR Reproducibility Checklist

31 July 2020; accepted 29 October 2020

Published online 6 November 2020

10.1126/science.abe1107 
A
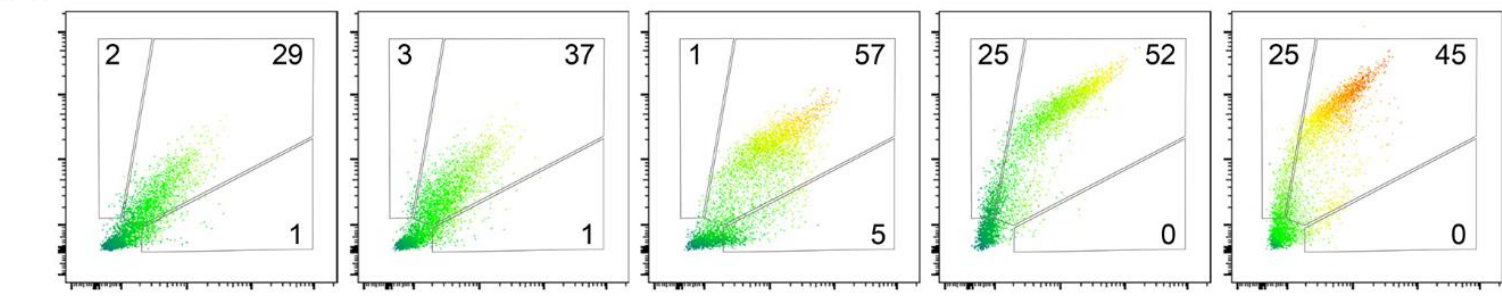

SARS-CoV-2 ${ }^{+}$
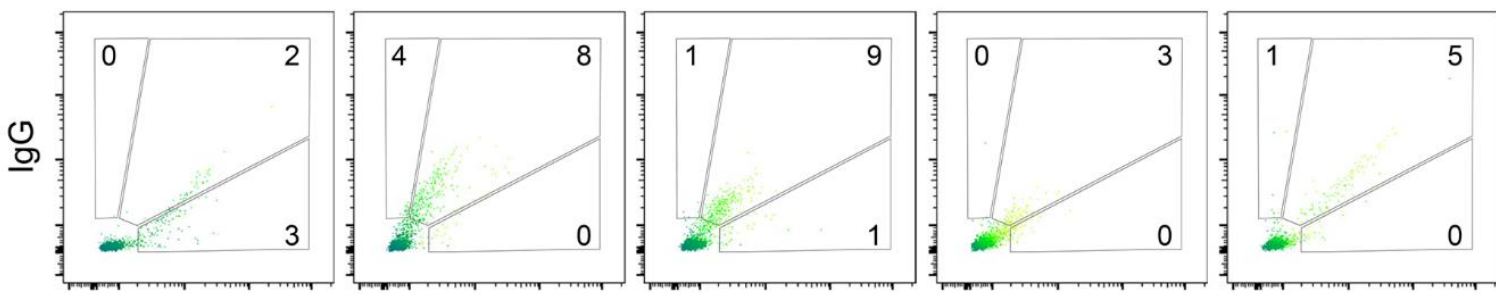

SARS-CoV-2-
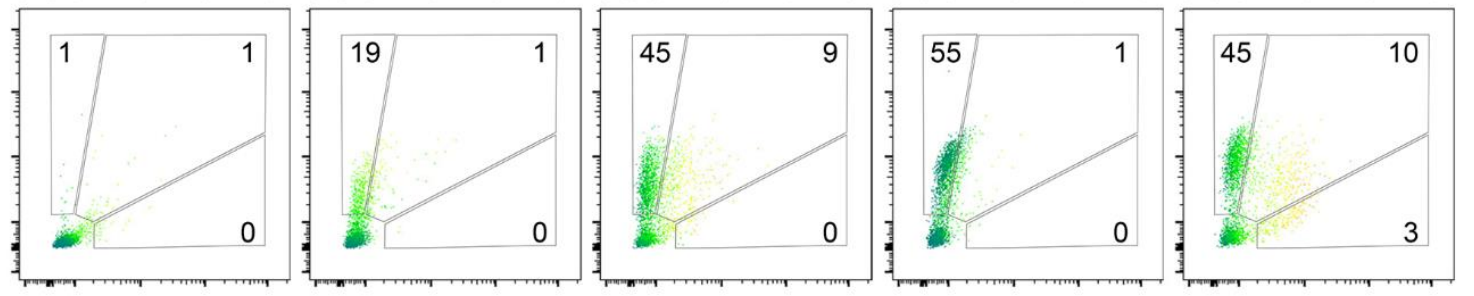

$\lg \mathrm{A}$

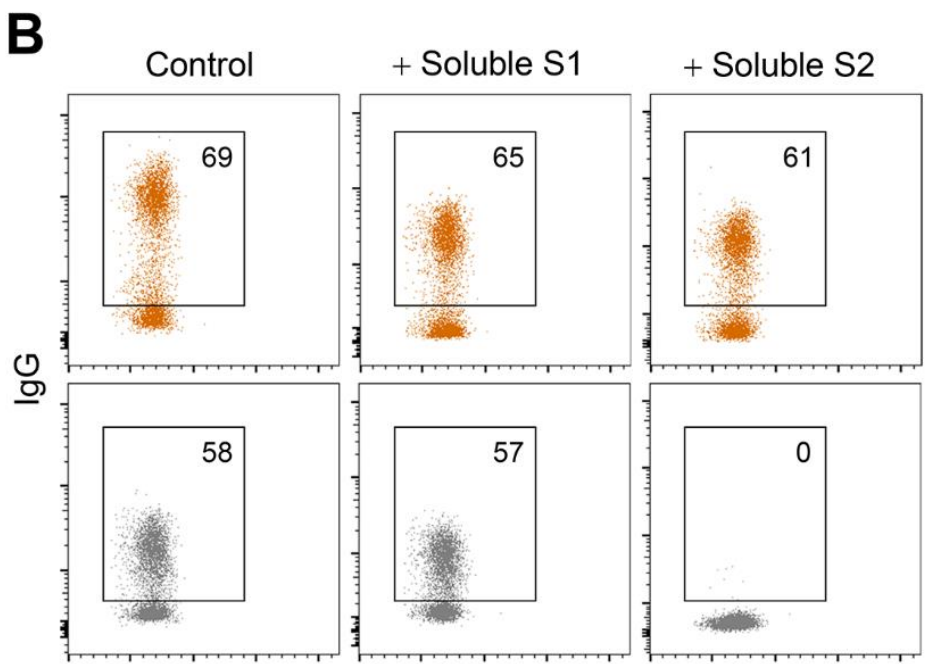

FSC

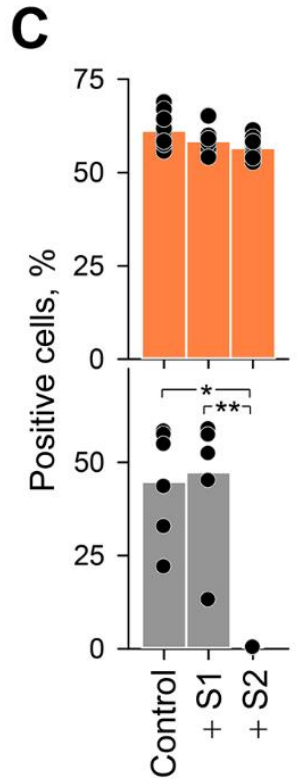

D

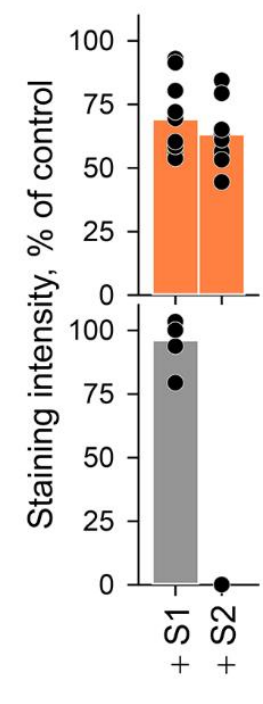

SARS-CoV-2 ${ }^{+}$

SARS-CoV-2-

$\mathrm{HCoV}^{+}$

Fig. 1. Flow cytometric detection and specificity of antibodies reactive with SARS-CoV-2 S. (A) Detection of IgG, IgA, and IgM in five individuals from each indicated group. IgM levels are indicated by a heatmap. (B to D) Inhibition of SARS-CoV-2 S binding of sera from SARS-CoV-2-infected (SARS-CoV-2+, n=10) or SARS-CoV-2-uninfected (SARS-CoV-2 $\mathrm{HCoV}^{+}, \mathrm{n}=6$ ) patients by soluble $\mathrm{S} 1$ or $\mathrm{S} 2$. Flow cytometry profile of one representative patient per group is shown (B). Mean frequency of positive cells (C). ${ }^{*} P=0.015$; ${ }^{*} P=0.006$, one-way analysis of variance (ANOVA) on Ranks. Mean staining intensity (mean fluorescent intensity (MFI) of sample as a percentage of negative control MFI) (D). In C and D, dots represent individual samples from one of three similar experiments. 

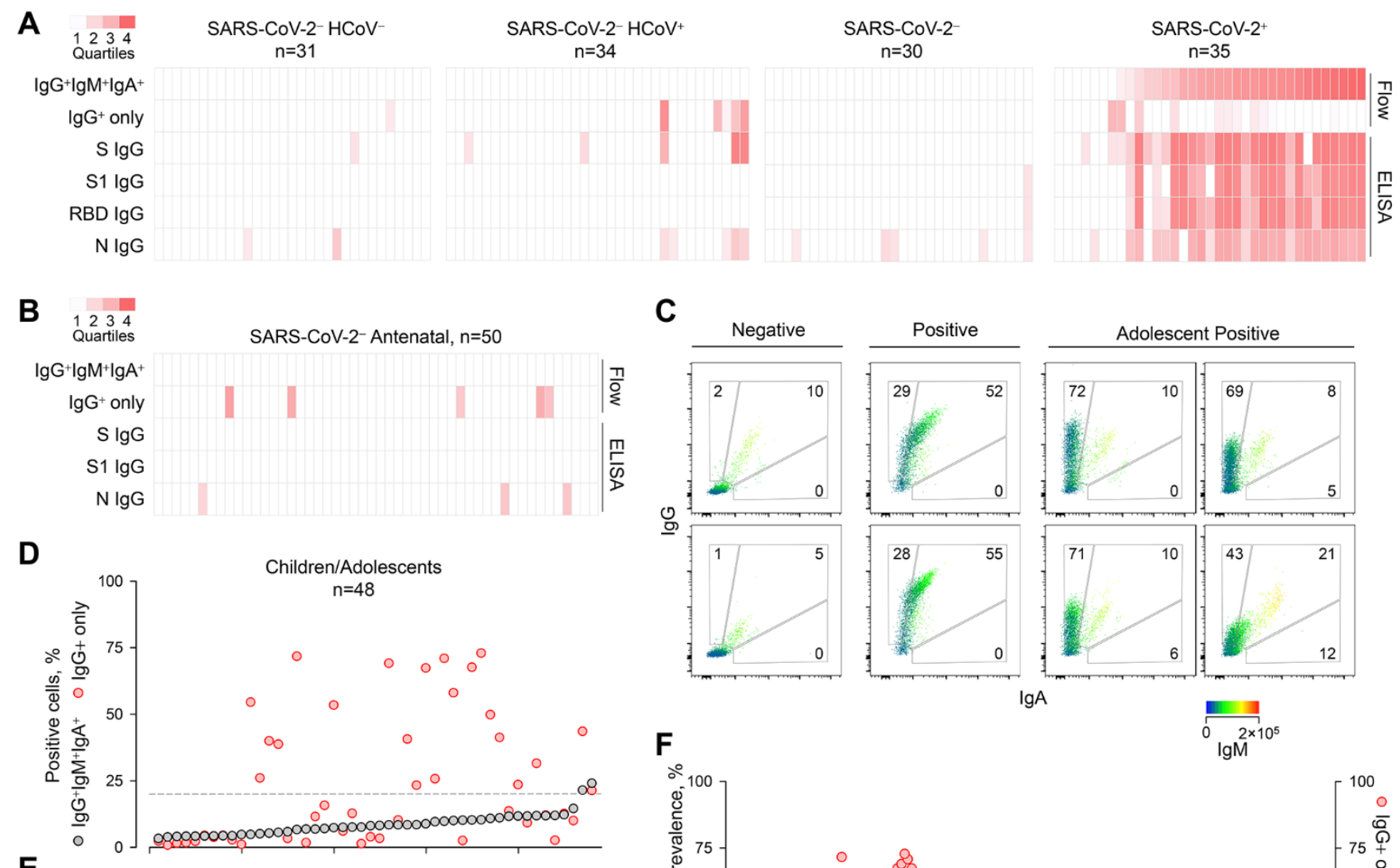

C

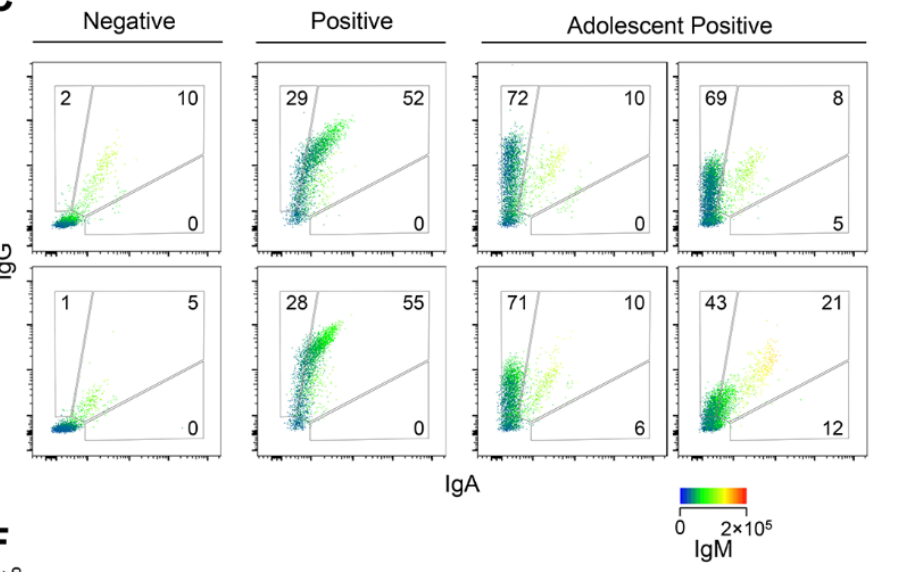

E
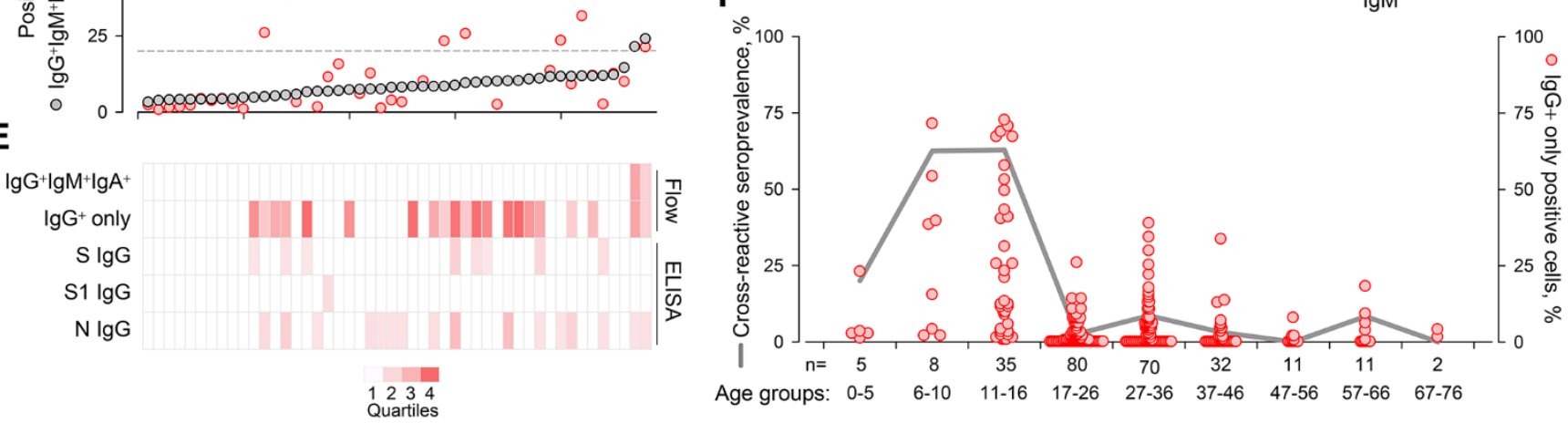

Fig. 2. Prevalence of SARS-CoV-2 S-cross-reactive antibodies detected by different methods. (A) Flow cytometry and ELISA results for each sample in cohorts $A$ and $\mathrm{C}$ to $\mathrm{E}$ (table S1). (B) Flow cytometry and ELISA results for serum samples from SARS-CoV-2-uninfected pregnant women. (C to E) SARS-CoV-2 S-cross-reactive antibodies in healthy children and adolescents. Representative flow cytometry profiles of seronegative donors (Negative) or COVID-19 patients (Positive) and of SARS-CoV-2-uninfected adolescents with SARS-CoV-2-crossreactive antibodies $(C)$. Frequency of cells stained with all three antibody classes $\left(\lg \mathrm{G}^{+} \lg \mathrm{M}^{+} \lg \mathrm{A}^{+}\right)$or only with $\lg \mathrm{G}$ $\left(\lg \mathrm{G}^{+}\right)$, ranked by their $\lg \mathrm{G}^{+} \operatorname{lgM} \mathrm{M}^{+} \lg \mathrm{A}^{+}$frequency (D). The dashed line denotes the assay sensitivity cut-off. Flow cytometry and ELISA results for each sample (E). (F) Prevalence of SARS-CoV-2 S-cross-reactive antibodies in the indicated age groups (line) and frequency of cells that stained only with IgG (dots) in all samples for which the date of birth was known. The heatmaps in A, B, and E represent the quartile values above each assay's technical cut-off. 


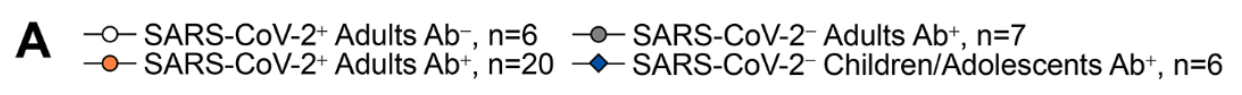

SARS-CoV-2 S pseudotype

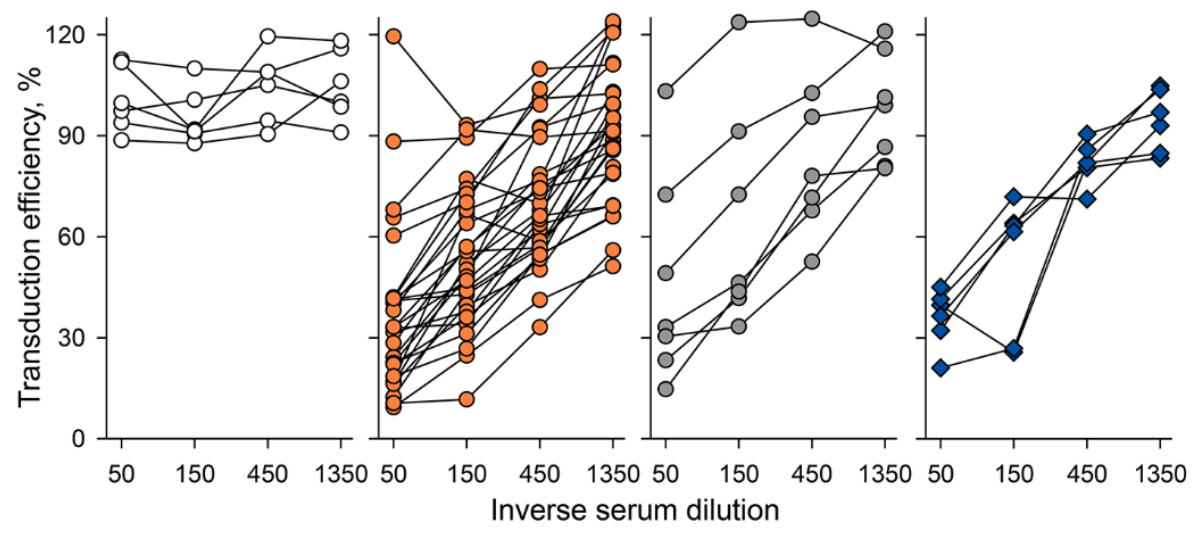

VSVg pseudotype
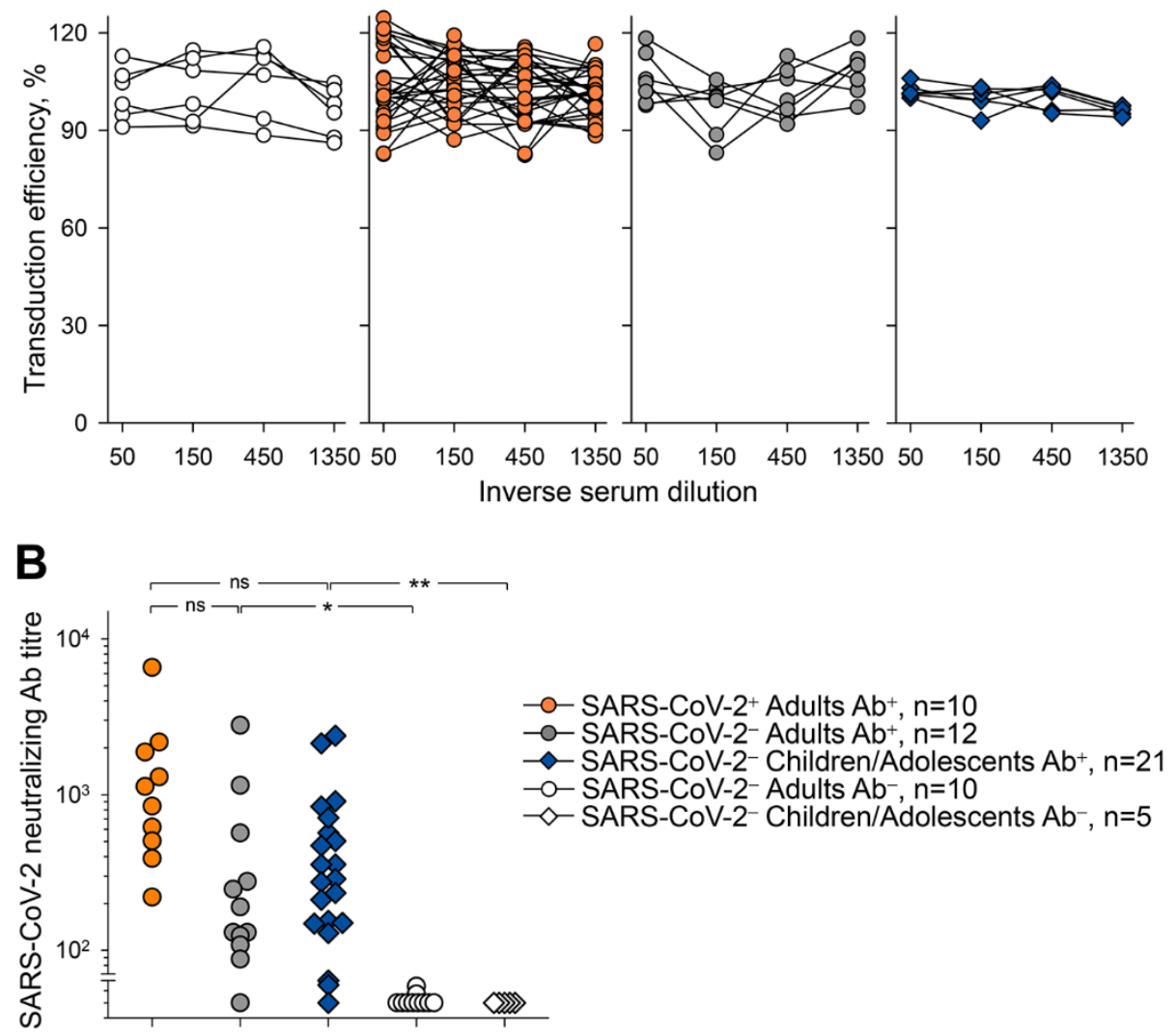

Fig. 3. Neutralization of SARS-CoV-2 S pseudotypes and authentic SARS-CoV-2 by SARS-CoV-2-infected and uninfected patient sera. (A) Inhibition of transduction efficiency of SARS-CoV-2 S or VSVg pseudotypes by adult

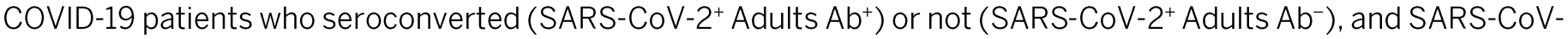
2-uninfected adult (SARS-CoV-2 ${ }^{-}$Adults $\mathrm{Ab}^{+}$) or children and adolescent donors (SARS-CoV-2Children/Adolescents $\mathrm{Ab}^{+}$) donors with SARS-CoV-2 S-binding antibodies. Each line is an individual serum sample. (B) Authentic SARS-CoV-2 neutralization titers of sera from the same donors as in A, as well as SARS-CoV-2uninfected donors without SARS-CoV-2 S-binding antibodies $\left(\mathrm{Ab}^{-}\right)$. Dots represent individual samples. ${ }^{*} P=0.037$; ${ }^{*} P=0.014$; ns: not significant, one-way ANOVA on Ranks. 
A
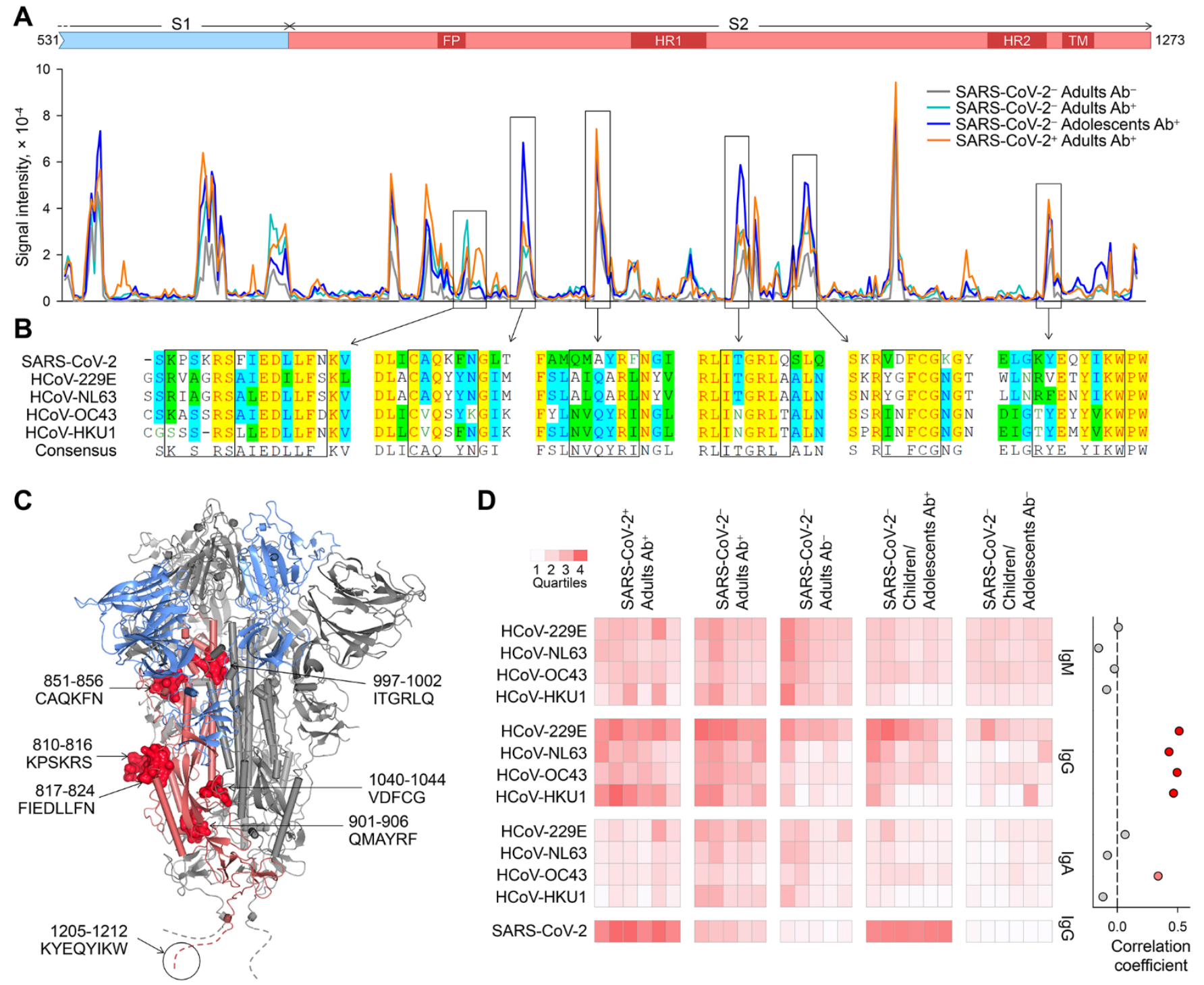

Fig. 4. Mapping of cross-reactive epitopes in SARS-CoV-2 S. (A) Signal intensity for each overlapping peptide along the length of SARS-CoV-2 S covered in the peptide arrays, using pooled sera with $\left(A b^{+}\right)$or without $\left(A b^{-}\right)$flow cytometry-detectable SARS-CoV-2 S-reactive antibodies. Differentially recognized peaks are boxed. (B) Alignment of the amino acid sequences of SARS-CoV-2 and HCoV S glycoproteins. Boxes indicate predicted core epitopes. (C) Mapping of predicted epitopes targeted on the trimeric SARS-CoV-2 spike. The S1 (blue) and S2 (pink) of one monomer are colored. Epitopes are shown for one monomer; the circled dashed line represent the membrane proximal region not present in the structure. (D) (Left), Reactivity with the S glycoproteins of each HCoV of the indicated sera with $\left(\mathrm{Ab}^{+}\right)$or without $\left(\mathrm{Ab}^{-}\right)$flow cytometry-detectable SARS-CoV-2 S-reactive antibodies, determined by flow cytometry. Each column is an individual sample. Rows depict the staining for each antibody class. (Right), Correlation coefficients between percentages of IgG staining for SARS-CoV-2 S and IgG, IgM, and IgA staining for each HCoV S glycoprotein. 